\title{
A Study of Routes to Enhancing Urban Soft Power Based on Human Capital
}

\author{
Li Qingquan
}

School of Economics and Management, Hunan University of Science and Engineering, Yongzhou Hunan, 425199

\section{Key Words: Human Capital ,Urban Soft Power ,Routes}

\begin{abstract}
Urban development has entered the competitive era of soft power. The sustainable development must focus on and build soft power, not just depending on extensive economic growth mode. It is not desirable to exchange extensive resource consumption and labor force at a low price for hard power. Moreover, human capital is of importance to soft power and considered a conclusive factor of modern economic growth and urban development. The article is an attempt to explore routes to enhancing urban soft power from the perspective of human capital.
\end{abstract}

\section{Comprehension of Human Capital from the Perspectives of Classic Writers at Different Times}

There is a long history of an opinion which manpower considered capital indicates how people affect the activities of production and economy. It is generally acknowledged that William Petty as a pioneer of Classic Economics uses the concept of human capital for the first time in western countries. However, Adam Smith, the originator of Classic Economics, officially expounds the basic ideas of human capital and provides a base for theoretical research in the history of economic theory. Later Marxism, who emerges as a new force, creates a brand-new theoretical system and explains its unique view of human capital, in sharp contrast to the ideas of human capital elucidated by vulgar Bourgeois Economics. Then Neoclassical School of Economics makes a point of human capital. The modern theory of human capital have not officially shaped and widely spread until the mid-20th century.

In Classic Economics, Adam Smith juxtaposes labor with capital and views labor skills as capital. In his eyes, human capital can be divided into two parts. One is circulating capital, one of general labor skills, in payment of salary so as to keep working. To increase income requires circulation and replacement of owners. The other one is fixed capital, one of special skills. The goal of higher income or profit can be achieved not by means of circulation and replacement of owners. For example, useful skills acquired by people in the society belong to the latter.

Marx thinks that the essence of capital is value which can bring about surplus value. Value can bring about surplus value, which lies in its purchase of living labor. Living labor refers to variable capital in which physical form is labor force that can create value. Actually, the said variable capital is human capital. In the field of vulgar economics, the view of Say is that human capital is divided into three types. They are general human capital, specialized human capital for professionals and innovative human capital for managers and executives. Mill thinks that family, education and health care are of great consequence and significance to human capital production. List puts forward a concept of mental capital in which spiritual stock of human capital and education are conclusive to national productivity.

Walras, a Neoclassical Economist, thinks that human resource equals to people and refers to population in terms of quantity. It is regarded as natural capital without involvement of labor, not one thing for transaction. But there exist supply and demand of labor and human service at the market. Human capital is evaluable. Marshall, a classic writer, puts forward a motto and theoretical foundation for modern human capital theory. He points out that economy is a course of research of wealth as well as that of research of human and human is one of major factors and only target for production. Human health and strength are fundamental to human capital. Industrial training is necessary for the skills requested by industrial efficiency, such as general education, industrial education and art education, etc. 
In the field of modern economics, Schurz thinks that human capital emerges on the basis of investment in people which is reflected in knowledge, skills, experience and proficiency related to people. In terms of monetary form, it is reflected in costs and charges caused by improving population quality and increasing time value of laborers, such as health care, on-the-job training, formal education, adult learning projects and employment migration.

\section{Human Capital and Construction of Urban Soft Power}

1The Importance of Human Capital to the Development of Urban Economy and Society

Economists view health, physical strength, production skills and production knowledge as capital stocks which constitute the increment in income in the future. In the field of economics, human capital is one of the theories to which experience is applied most and plays an increasingly prominent role in the practice of economy in various countries. Human is a special and important existing form of capital. In modern economics, human capital is divided into general and specialized human capital. Specialized knowledge and skills and human capital accumulation may produce increasing returns, which brings about higher income of other input factors and produces increasing returns to scale. Human capital is a decisive factor and permanent power in the course of growth of modern economy. It is conclusive to economic growth of a city and development of economy and society. Discrepancies in economic growth among regions and cities are mainly attributed to discrepancies in accumulation rate of human resources as well as comparative advantages of elements of human capital in the course of international trade. The development of human capital is beneficial to transforming economic growth from extensive pattern to intensive pattern, promoting industrial development and optimization and upgrade of industrial structure, improving cognitive ability and ideological and ethical standards and renewing ideas and changing life styles. All these provide intellectual support and spiritual motive force for the development of economy and society and help to build a harmonious socialist society. The fundamental issue of economic development is to raise human capital and add human capital accumulation. Moreover, human capital theory is of great importance to strategic choice and governmental decision. Basically, the development of a city relies on the development of people. It may get the support from the masses by means of improving social security measures, safeguarding social fairness and justice, focusing on people's livelihoods and bringing benefit to members of society. It is useful to promoting the development of people and attracting excellent laborers from other regions and cities. All kinds of laborers move to local cities, especially high-quality and highly-educated laborers or even laborers with skills, which saves cost devoted at earlier stages, such as education and medical treatment, increases the total amount of human capital at local cities and makes local cities and regions more competitive.

\section{Construction of Urban Soft Power and Human Capital}

The theory of soft power stems from the theory of national power at earlier stages in western countries. It firstly emerged in Soft Power: The Means to Success in World Politics written by Joseph S. Nye in the 1980s. He points out that a country' s comprehensive national power covers not only hard power, such as military, technology and economy, but also soft power, such as culture, ideology and attraction.

A city is a social and economic center in a region. Its influence to surrounding regions mainly comes from the comprehensive effect of elements of society and economy. Urban soft environment and hard environment determine whether a city is developed or not. To promote urban soft environment works closely with construction of urban soft power. Urban soft power is reflected in the role of a city in the course of taking part in development and competition. The city plays a role in its cultural influence, amenity, cohesion, innovation, regional force and coordination, depending on immaterial elements such as urban culture, governmental service, population quality, social harmony and image communication. There are some points which should be noticed in the course of constructing urban soft power. Firstly, urban position is clear, inclusive of levels of development of urban economy and society and opinions for the city from the outside world. Secondly, urban 
target is clear, such as what should be achieved based on construction of urban soft power. Thirdly, there is a clear understanding of what the environment is like and that of advantages and disadvantages in the course of constructing urban soft power. In other words, consider how to raise soft power and how to complete construction of soft power. Fourthly, plan is clear, such as what should be emphasized.

To raise urban soft power should start with the following measures. The first point is to highlight a city' s opening up to the outside world and to make the city more international. The second one is to create a unique spirit of the city depending on its own culture. The third one is to cultivate its distinctive culture and to develop cultural industry. The fourth one is to improve both soft environment and hard environment and to construct low-carbon city. The fifth one is to pay more attention to innovation and technology so as to enhance urban core competitiveness. Human resource plays a key and decisive role while raising urban soft power. People are origin of advanced productivity. To fundamentally raise urban soft power relies on accumulation, development and utilization of human capital. The five measures mentioned above are closely relevant to human capital. To raise urban soft power is beneficial to accumulation of human capital which in turn promotes construction of urban soft power. They are dialectical unity.

\section{Routes to Enhancing Urban Soft Power Based on Human Capital}

There is a long history of the ideas of human capital which have spread and evolved for nearly half century. The great significance of investing in human capital has been widely acknowledged by both all sectors of society and decision-making sections of the government. Human capital is decisive to growth of modern economy as well as development of society. Human capital is one of key parts of urban soft power. To develop and accumulate human capital are of great importance to enhancing urban soft power. Therefore, routes to enhancing urban soft power based on human capital are as follows:

1To Balance Urban and Rural Human Capital Development

Rural people account for over $50 \%$ of Chinese population. With the exception of most cities on the East Coast, rural people constitute the main part of human resource. As to development of human resource, the government should attach importance to accumulating urban human capital and developing human resource, while ignore those in the rural areas. Consequently, guided by Scientific Outlook on Development, we push ahead with construction of a new socialist countryside and pursue our efforts in developing rural economy and society for the purpose of building a harmonious socialist society. We promote integration of employment and build a vocational training system covering urban and rural areas and pay more attention to introducing and implementing policies concerning rural areas, such as training subsidies and occupation introduction subsidies. We open the windows especially for serving peasant laborers and advise them what those policies are so as to accelerate the transfer of rural surplus labor forces. We give definitive protection to rural people, adopt a minimum wage, supervise the owners who employ peasant laborers and even enhance the ability to administrate the contracts for peasant laborers.

\section{To Accelerate Accumulation of Human Capital}

In the field of modern economics, human capital is conclusive to urban and economic development and one of the most strategic resources for urban soft power. According to Schultz' $\mathrm{s}$ view, human capital includes health care, formal education, on-the-job training, adult learning projects and employment migration. How a city accumulates human capital should start with the following points. The first point is to implement and improve measures which focus on health care. It is of great importance to protecting people and maintaining human capital. They are commonly regarded as realization of sustainable development of people. The second point is the most important and the most basic measure which reaches the goal for accumulating human capital. It is also critical to completing the transfer from population resource or population pressure to human resource. Specifically speaking, it means prioritizing education, prospering the nation with science, education and talent and doing a good job of basic education and quality education. The third point is to establish a perfect system for vocational training and accelerate development of vocational 
training. Employees begin to work only after passing vocational training course and then obtaining a certificate for skill levels. Vocational training is stipulated and regulated by the nation according to the standards for occupational specification and skills. Vocational training helps to make sure laborers are equipped with basic skills and professional skills and they are qualified for their jobs, which complete the transfer from general human capital to specialized human capital. The fourth point is to improve administration of all kinds of adult learning projects and make them more systematic and formal. The government pays more attention to supporting adult learning projects, carries out financial subsidies and encourages all sectors of society to set up night schools for adults, training schools and training companies. The government helps individuals overcome their shortcomings and the harm of Cannikin Law so as to ensure balanced development of individuals. The fifth point is to break the dual structure of urban and rural economy as soon as possible. In other words, the government improves its own behavior, protects basic rights concerning laborer immigration and makes a commitment to fair treatment of immigrated laborers so as to promote reasonable immigration of human capital.

\section{To Establish a Healthy and Incentive System for Human Capital}

Incentive theory provides summarization of how to satisfy human needs and how to motivate people. The theory points out that people deliver better results by means of making full use of right motivation and intelligence and inspiring one' s initiative and creativity. According to Maslow's Hierarchy of Needs, there are five types of human needs which come together like a ladder. Five levels of human needs are upgraded progressively, ranging from physiological needs regarded as the most fundamental level of needs at the bottom, safety needs, love and belonging, esteem and the need for self-actualization at the top. Incentive proves to be a catalyst for the release of energy. A city must build and emphasize an incentive system for income distribution in order to attract and retain talent by means of conducting activities in accordance with the idea of putting people first. The incentive system essentially equals to motivating people and setting up and improving the systematic and integrated incentive system for human capital. As to Maslow's Hierarchy of Needs, to motivate people should start with different levels of human needs and pay more attention to satisfying the need for esteem and the need for self-actualization. The measures concerning the incentive system for human capital aims to boost cohesion and attract various kinds of human capital, especially specialized human capital and innovative human capital.

\section{To Improve the Management of Human Capital}

At present, there is more information about the management of human resources. By contrast, the management of human capital is scarcely mentioned. Specifically speaking, the management of human capital refers to maintaining and increasing value of human capital by means of various measures guided by the ideas of economics and people-oriented thought. The management of human capital should be systematic, scientific, people-oriented and flexible. The first point is systemic management of human capital which needs to make a forward-looking plan for developing and managing human capital in order to realize sustainable development of human capital. The second point is scientific management of human capital. The management of human capital balances a relationship among general human capital, specialized human capital and innovative human capital guided by Scientific Outlook on Development so as to coordinate various kinds of human capital. The third point is people-oriented management of human capital. Fundamentally, to manage human capital is to manage people who are living. They are not controlled simply by outside forces. They are selective and have values of their own. Therefore, as to the management of human capital, it is conclusive to put people first and combine improvement of individuals with accumulation of human capital as a whole in order to promote all-round development of people. The fourth point is flexible management of human capital. Construction of an organizational structure and that of the flexible system for developing and accumulating human capital may be completed by means of adapting to the change of outside environment, keeping up with the times and adjusting strategies for managing human capital in time. 


\section{References}

[1] Li Baoyuan. Human Capital and Economic Development[M]. Beijing Normal University Publishing Group, 2001.

[2] Zhou Sanduo, Chen Chuanming. Principles of Management[M]. Nanjing University Press, 2007.

[3] Sun Liang. China's Model of Development and Construction of National Soft Power[J]. Comprehensive Competition, 2010, (02): 92-96.

[4] Jiang Jizheng, Tang Shuguang. Study on Urban Soft Power of Changsha City[R]. Changsha: Research Office of Changsha Municipal People’s Government, 2010.

[5] Chen Li, Xiong Ying, Sun Yiping. Study on Integrated Strategies of Balancing Urban and Rural Development of Human Resource[J]. Chinese Talents, 2011, (01): 68-70.

[6] Ru Xifang. From Resource to Capital—On Human Capital[J]. Market Modernization Magazine, 2011, (20): 120-121.

[7] Yang Haijun, Ling Wenquan. Flexible Strategies for Human Resource in the Post Financial Crisis Era[J]. Modern Management Science, 2011, (02): 20-21, 28.

[8] Chen Wenjun. Human Capital, Employment Opportunities and Rural Laborers Immigration of China[J]. Southern Forum, 2004, (03): 118-124.

[9] Qiao Defu. On Features and Effects of Human Capital[J]. Human Resource Development of China, 2003, (03): 70-72.

\section{Author in brief:}

Li Qingquan (1964 - ), male, ,professor.,. mainly engaged in economic theory and regional economy..E-mail:Liqingquang369@163.com 